\title{
Government Sponsored Social Media Projects in Agricultural
}

\section{Extension}

\author{
Sudhakar B* \\ Assistant Professor, Department of Agricultural Extension, Faculty of Agriculture, \\ Annamalai University, India
}

*Corresponding author: Sudhakar B, Assistant Professor, Department of

Short Communication

Volume 3 Issue 7

Received Date: August 04, 2018

Published Date: August 31, 2018 Agricultural Extension, Faculty of Agriculture, Annamalai University, Chidambaram, Tamil Nadu, India, Email: ban_sudh@rediffmail.com

\section{Abstract}

Social media is an innovative tool for technology transfer in communication process. As the communication process started form ancient times with some basic means of communication as mentioned by Aristotle Speaker-SpeechAudience. Nowadays tremendous development in communication system with advance communication tools like ICT (Information and Communication Technology), Multimedia, Internet, e-mail and now very popular and trendy aspects in communication system is social media. In social media different communication tools like Whatsapp, Facebook, Twitter, YouTube, Instagram, LinkedIn, Agripedia, Wikipedia, Research Gate etc that are all using by the peoples with Android mobiles. Smart phones, Laptop, Tabs etc. In Agricultural extension point of view the social media play a active role in transfer of agricultural technologies. The Government play an important role by makes use of farmers by providing schemes and projects throughout the world. This paper highlights the Government sponsored social media projects in agricultural extension in different countries especially in India and Australia.

\section{Introduction}

In ancient period communication was carried out by non-verbal means (postures, signs, symbols etc) and verbally by face-to-face communication, using dove, spy men, diplomats etc. That period not have any development in communication. In 17th century with commencement of postal system and 18th century started telephone system peoples start communication in easy way in the western countries and slowly spread to other countries in 19th century. But in 20th century vast development in the communication aspects such as telecommunication networks all over the world viz., landline, pager, mobile, broad band and internet connectivity etc. This was due to advanced satellites launched in to the space especially for information and communication purposes. In 21th century, the entire world change in to 'information village' by most advanced communication development like smart phones, android phones, cheap internet and broad band connectivity, 2G, $3 \mathrm{G}, 4 \mathrm{G}, 5 \mathrm{G}$ connections, Wi-Fi connections etc. This is the pathway of development of social media. Social media 


\section{Open Access Journal of Agricultural Research}

refers to the internet-based digital tools for sharing and discussing information among people. It refers to the user generated information, opinion, video, audio, and multimedia that is shared and discussed over digital networks [1]. Regarding the agricultural extension field, technologies transferred to the farmers is their major role. Now communicating information to the farmers by quick, easy, low cost, efficient and effective scientific and technical knowhow aspects advises by the scientist, researchers, faculties, extension functionaries. Hence, social media would be essential for agricultural extension in technology transfer aspects. The government and private sectors initiatives for social media development would be limited in both developed and developing countries [2]. This paper highlighted the government sponsored social media project in India and Australia. This project will be useful to the researchers, extension functionaries, farmers etc.

\section{Kerala Government Sponsored Scheme}

Annual plan (2017-18) Kerala government sponsored scheme on "Integration of social media for agricultural development for strengthening of agricultural extension" [3]:

The main objectives of the scheme are:

1. To explore the potential opportunities of social, digital media, mobile and interactive web service platform and to integrate those platforms for the effective information dissemination and advisory service among the farming community in Kerala by using krishi.info portal as a single window system for the convergence of all ICT media tools like e-mail, mobile phone, fax and social media channels like Facebook, Twitter, Blogs, LinkedIn, Pinterest, Whatsapp, SMS, MMS (Multi Media Service) facility being developed as a part of "Karshika Vivara Sanketham Project".

2. To promote Kerala based social media groups for strengthening cyber extension and to enhance production, productivity and profitability of farming in Kerala by using krishi.info portal of "Karshika Vivara Sanketham" as a centre point and integrating this to all other applications, web portals and social media channels. This will increase the reach of extension activities of the Department through maximum networking at different tiers like State, District, Block and Krish Bhavan.

3. Positive and proactive engagement with social media for dissemination of modern scientific agricultural innovations to farmers and to bring maximum registered farmers to social media, in case of farmers who are not proficient in modern digital technologies and social media. Lead farmers/Master farmer from the group will be given incentive to spread new technology to such farmers and interact with social and digital media platforms. Promotion of marketing activities by the use of e-Vipani Mobile App and e-commerce portal being developed by SFAC (Small Farmers Agri-Business Consortium).

4. To attract, encourage and motivate NRIs (NonResidential Indians), ex-service men, youngsters, women and professional to farming in Kerala and also self help groups like Kudumbasree and other farming clusters.

5. To disseminate scheme information, support from Agricultural Department and assistance to social media group members for the development of Agricultural Sector in Kerala.

6. To encourage and motivate social media participants to provide Agricultural Support Services to farmers by providing cash prizes to best social and digital media groups and apps.

7. To provide Training and connect farmers to authentic sources of information regarding availability of quality inputs through social media participation to encourage more people to adopt scientific farming in Kerala.

8. To form a Digital Sena of experts consisting of Karshika Vivara Sanketham experts, Agricultural Department officials, Techno savvy Master Farmers, Experts, Agricultural Graduate and Postgraduate Students to authentic information for farmer engagement.

9. To bring all the Agriculture based online group under the umbrella of the Web Portal 'krish.info' and mobile apps for farmers and department officials being developed for "Karshika Vivara Sanketham".

10. To encourage Agricultural Department officials to participate in social media by providing cash prizes.

11. To train Agricultural Department officials in using social and digital media for enhancing the effectiveness of extension and dissemination of information and discuss about trending topics in the field of Agriculture.

12. To develop a social and digital media policy for Agricultural Department in compliance with the guidelines of Government of India and Kerala.

13. To get real time response and feedback of schemes from farmers for effectively planning, implementation and monitoring of schemes resulting in seamless farmer experience.

14. To identify and popularize farmer level effective innovations and Good Agricultural practices.

15. To continuously improve the efficiency and effectiveness of service delivery of Agricultural Department with farmer focus by constantly engaging with farmers, consumers, agricultural experts, input dealers, students and all stakeholders of Agricultural 


\section{Open Access Journal of Agricultural Research}

Department in Kerala and to solve issues and complaints related to service delivery by integrating with "Karshika Vivara Sanketham" with portal. Mobile app and other portals and applications developed for Agricultural Department by IIITM-K, NIC (National Information Centre) and KAU (Kerala Agricultural University). To help farmers to adopt the best Agricultural Scientific Practices and crowd sourcing more funding and technology from all over the world to local farming community and groups with the participation of field level officers.

16. The proposed convergence platform will function to promote the Organic Agricultural Policy of the state by supporting Good Agricultural Practices, organic farming, Safe to eat produces, Ecological Engineering and Urban Agriculture.

17. To link existing e-governance tools like farmer registration and Electronic benefit transfer data to the krishi.info portal to provide a single window system to get all information at a single point.

\section{Potential Social and Digital Media Platforms to be used for Extension in Kerala}

Facebook, Twitter, Blogs, LinkedIn, Pinterest, Whatsapp, Instagram, YouTube, Websites, Flickr, Slideshare, Mobile Apps based Agri-Advisory Services, SMS, Voice messaging, USSD (Unstructured Supplementary Service Data) code etc, Sound Cloud, FM and Online Farm Radio Services and other new age social and digital media platforms/applications, tools and technologies etc.

All new age social and digital media platforms will be integrated with Krishi.info portal developed for Agricultural Department under "Karshika Vivara Sanketham Oru Viralthampil Project".

Total cost of the project is Rs $1,10,000,00$. Deputy Director of Agriculture (Extension and Training) of the Districts will be incharge of the implementation of the scheme at the District level. At the State level Additional Director of Agriculture (Extension) will monitor the implementation of the scheme.

ATMA may create district level Facebook pages/blogs. These pages can be linked to the krishi.info portal of "Karshika Vivara Sanketham" of SFAC. ATMA District level Team should share weekly messages and technologies advice to block and Krishi Bhavan level officers for sharing through social media platform.

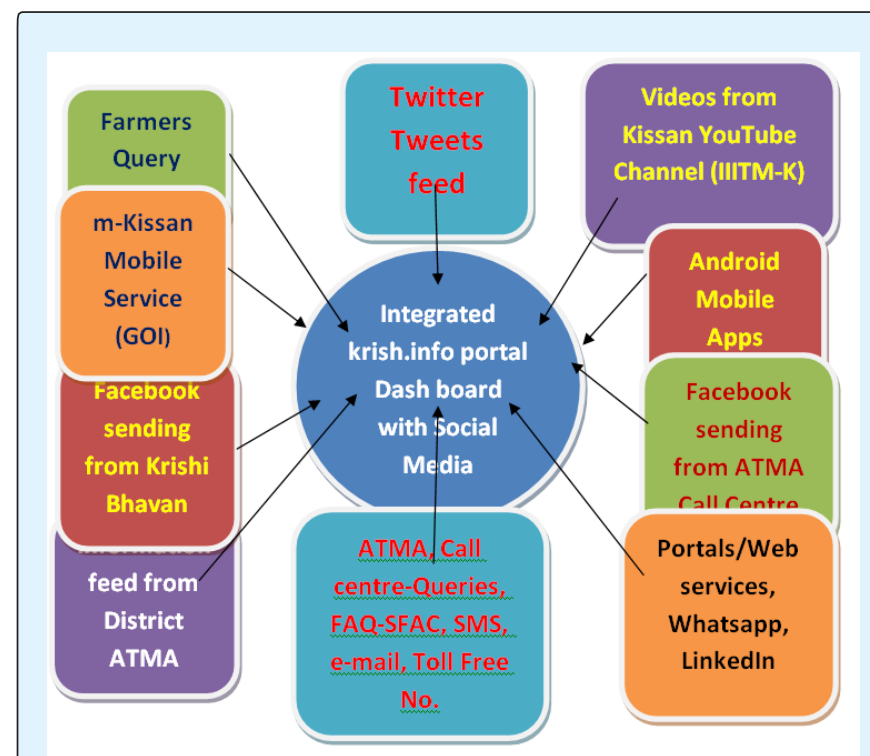

Figure: Integration Architecture.

\section{Data Plan Support to Krishi Bhavan, Lead Farmers/Master Farmers}

The Assistant General Manager, BSNL has provided a special data plan for Agricultural Department. Farmers and officers who have joined the data plan should report product for marketing in e-commerce portal/e-Karshika Vivara Sanketham on a weekly basis. Lead farmers who have actually reported to data should be selected for adding to the new plan. Krishi Bhavan officials and Lead/Master farmers who receive data plan should use this to share modern scientific agricultural information using e-extension tools and techniques through social media like Whatsapp, Facebook etc to farmers leaders and farmers regularly. They should update social media platforms of technological department regularly and share agricultural knowledge with other farmers and effectively use social media tools for e-extension.

In case of any field level problems they should communicate with social media enabled call centre portal www.krishi.info of "Karshika Vivara Sanketham Oru Viralthampil Project" (Toll free No 1800-425-1661, Whatsapp No +91 944705 1661, Facebook fb.com/Krishi info) Krishi Video Mobile App (www.krishivideoadvice.gov.in), Research Stations/KVK's and other institutions where experts/solutions/technology are available using photos/videos/audio/accurate description of field problems and share the solutions received from experts to farmers. The data plan holders should effectively 


\section{Open Access Journal of Agricultural Research}

showcase and share demonstrations results, new agricultural practices, success stories, scheme information and achievements of Agricultural Department and Farmer Welfare Department using social media. New advisories, messages received from ATMA District Team/KVK/Other institutions should be shared with maximum beneficiaries from registered farmers of the Department through social media.

IT Division of Agricultural Department will issue detailed guidelines for the effective use of social media for Agricultural extension activities. Official users of social media should comply with the guidelines of draft social media policy of Government of India, IT Act 2000 and instructions from State Govt. and Agricultural Department issued from time to time. IT Division will create social media platforms for sharing scheme and related information to various Agricultural Department offices.

\section{Australian Government Sponsored Project}

Stanley, K and Mandy Pearce reported that the Social Media in Agriculture is an innovative project that would explore the use of social media (You Tube, Vimeo, Facebook, Twitter, RSS, etc.) as an extension tool. The project is part of an ongoing commitment of the "Ag Excellence Alliance" to supporting grower groups across the state and is funded by Australian Government's Caring for Our Country. Through this project, short videos would be produced and loaded onto social media internet sites to assist with delivery of agricultural extension around soil condition and landscape and soil conservation in South Australia. The project was shared information on new and innovative farm practices $[4,5]$.

Ag Ex anticipates that there will be many uses for the video clips including:

- Presentations at field days, conferences and other events.
- Providing instruction and demonstrations of new and innovative practices in the paddock through i-phone access via Vimeo and YouTube.

- Use in training activities and promotion of project achievements on the internet for wide spread access.

The project is targeting the 15 farming systems groups that have an association with the "Ag Excellence Alliance" and its network partners including advisers, agribusiness, relevant state and Australian government agencies and the state's eight natural resource management organizations. Social media in agriculture aims to build the skills of groups and individuals in the use of social media. 40 high quality videos were produced. Crop grower, group members and advisors should also have an opportunity to participate in training in the use of social media and making videos, to allow to them to be at the leading edge of these technologies in the future.

\section{References}

1. Andres D, Woodard J (2013) Social Media Handbook for Agricultural Development Practitioners. USAID and FHI 360.

2. Sudhakar B (2018) Social media: An-Innovative Tool for Technology Transfer in Agricultural Extension. Agrobios India Publication.

3. Annual plan (2017-2018) Kerala government sponsored scheme on Integration of Social Media for Agricultural Development for Strengthening of Agricultural Extension. Directorate of Agricultural Development and Farmers Welfare. Vikas Bhavan, Thiruvananthapuram.

4. Stanley K, Pearce M (2013) Social Media in Agriculture "Ag Excellence Allience".

5. Mayfield A (2008) What is Social Media? 